\title{
Political correctness and linguistic creativity in the job market. How much do they (mis) inform?
}

\author{
Ilona Delekta \\ University of Silesia in Katowice, Poland \\ ilona.delekta@us.edu.pl
}

\begin{abstract}
The article examines how political correctness (PC) affects work-related lexis. A particular focus is put on English bizspeak that aims to fulfil PC demands by using creative vocabulary and euphemisms to motivate employees, stimulate their creativity, and win or keep customers. A brief theoretical outline is followed by an analysis based on authentic material. The results show that such colourful language may contradict PC postulates and impede effective communication.
\end{abstract}

Keywords: political correctness, bizspeak 


\section{Political correctness and euphemism}

Political correctness (PC) is a kind of social code related to language, behaviour and opinions aimed at avoiding giving offence to people who are members of various minority groups. PC in language aims at eliminating lexis that could hurt people's feelings, cause their exclusion or discrimination. This article focuses in particular on the language of business, also called bizspeak, corpospeak, management speak, corporate lingo or spinglish ${ }^{1}$ and the linguistic devices it uses to convey some 'uncomfortable' issues. These are often euphemism and euphemistic expressions. Euphemism comes from Greek (euphemismos, eu [good, well] and pheme [speech]), and is a mild word or expression that replaces one referring to taboo issues which people might find offensive, embarrassing or unpleasant. However, researchers attempting to provide a more comprehensive description of euphemisms and taboos face a challenge because of the multitude of various factors affecting euphemisms such as their origins, their social, cultural and linguistic contexts and their functioning. Rozlach-Szymczyk (2014) emphasises that the complexity of linguistic and non-linguistic issues requires that euphemisms and taboos be investigated with multi-disciplinary approaches. So it is a research subject that spans the disciplines of linguistics, psychology, culture, sociology, anthropology, politics and business to mention but a few. Taboos can be divided into old fear-based taboos and modern-day taboos. The former are mostly related to magic and religion, illnesses and people and things that are thought to be physically or spiritually unclean. Krawczyk-Tyrpa (2001) distinguished six types of fear-based taboos in the language: names of gods, demons, magic, death, illnesses and nature. She also indicated (ibid) that creating such euphemisms was natural since people fear everything that is different or alien: "Human beings feel weak and powerless, and cannot cope with forces that overpower them." According to Allan's naturalist hypothesis (1986) people believe that "the proscription against uttering certain lexical forms stems from an ancient belief that words possess the capacity of influencing and altering reality and the form of an expression somehow communicates the essential nature of whatever it denotes." In other words, it is believed that some words have a power that might change reality and, for example, bring good or ill fortune and cast bad spells. Merlan (2006) illustrates this thesis with examples from Chinese and Japanese: the Chinese avoid the word four because it sounds like the word death, and Japanese wedding speakers are forbidden to use words that mean leave, list, exist, severe, back, sever and suffer. Modern taboos include a number of -isms such as racism, sexism, ageism and religionism. So the current response to modern

1 Referring also to the language of politics and spin doctors 
taboos focuses on people and how to talk to and about them without causing offence, in particular people who might be excluded or disadvantaged. Ullmann (1969) distinguished three reasons for creating and using modern euphemisms: taboo of fear, taboo of delicacy, taboo of propriety. Others also mention issues such as taboos connected with the human body; bodily functions; death or sex; various cultural, moral or religious issues; superstitions; politeness; social norms of politeness or gentility; being well-behaved; empathy or censorship (both selfcensorship and political censorship). As mentioned above, taboos are connected with certain forbidden linguistic and non-linguistic behaviours. This article focuses mainly on the linguistic relationship between taboo and euphemism in business communication.

These two notions are closely connected. Euphemism replaces forbidden words or expressions or, in some cases, taboo topics are not raised or discussed. It should also be mentioned that euphemisms are dynamic since they evolve over time. Their connotations change, some in a positive direction (amelioration) and others in a negative direction (pejoration), and others become their opposites (dysphemisms) and are replaced by new euphemisms. This shift in meaning is called the euphemism treadmill (Pinker 2003). Below are two examples illustrating the search for more PC language and the transformation of terms related to disability and soldiers' health:

- Crippled $\rightarrow$ handicapped, disabled $\rightarrow$ people with disabilities or the acronym PWD

- $\quad$ shell shock (World War I) $\rightarrow$ battle fatigue (World War II) $\rightarrow$ operational exhaustion (Korean War) $\rightarrow$ post-traumatic stress disorder (Vietnam War)

Euphemisms are also used as a stylistic or rhetorical device for embellishment or humorous effect in show business, advertising or marketing.

Euphemisms can be created in different ways: replacing them with metaphorical words and phrases which evoke associations with the basic meaning of the word or phrase (e.g. pass away instead of die), using only the first letter of a forbidden word (F-word), using the pronoun it (e.g. in the sentence "they did it", it refers to some undesirable activity). By no means can this list be regarded as complete as the creativity of euphemism creators is unlimited. 


\section{Research scope and method}

This study investigates how euphemism is used in a business context and describes its two functions: improving function and creative function. In order to illustrate this, the author uses samples of authentic English language excerpted from the BBC, CNN, The Guardian, Wall Street Journal, LinkedIn and other sources indicated in the text. This is a descriptive study based on an analysis of current English language samples from English-speaking countries in the last five years judging by the dates of their publication or release. These two sampling criteria - English-speaking environment and period of time - makes it possible to draw the conclusion that the new euphemistic lexis was created by English native speakers approximately at the same time and is relatively up-to-date. For this reason most lexical items are taken from the press and websites to ensure compliance with the criteria as books take a long time to publish. There is also a brief overview of literature presenting various aspects of euphemism as well as other issues related to the rapid development of bizspeak and its consequences in the workplace and business.

\section{1 Euphemism: improvement and camouflage}

According to Engelking (1984), having to refer to inappropriate, unpleasant or drastic things or issues is the primary reason for creating euphemisms. In these "difficult" situations euphemisms play the defensive role of avoiding references to inconvenient or hostile reality, which is done by replacing "bad" expressions with more appropriate positive ones. Thus, the use of euphemism makes language sound less categorical or hostile.

McGlone, Beck and Pfiester (2006) point out that euphemism has a camouflage-like property, which poses a certain risk since it can lead to language manipulation, loss of actual meaning and distraction from the message. This can be illustrated by the phrase alternative facts used by the Trump administration to disguise untrue statements or blooming euphemistic bizspeak. Other "interesting" ways of expressing a similar idea include: deviating from the truth, sailing under false colours, playing fast and loose with the facts and giving a false colouring to the facts.

The first group of improving euphemisms presented in this article involves vocabulary used to refer to people, and their work and job duties. There is an impressive amount of vocabulary related to dismissal and being dismissed. Some of the nouns, noun phrases, verbs and verb phrases are presented in Table 1 below. They mainly come from the article by Peters (2017). 
Table 1. Dismissal-related euphemisms

\begin{tabular}{|l|l|}
\hline TO BE DISMISSED & DISMISSAL \\
\hline to be attritioned & the process of destaffing \\
\hline to be graduated & orderly ramp-down \\
\hline to be decruited & talent calibration \\
\hline to be excessed & work imbalance correction \\
\hline to be transitioned & Transition \\
\hline
\end{tabular}

As can be seen, the new, improved lexis has more positive connotations than dismiss / dismissal. However, it seems that the denotations of the PC terminology can prevent employees from understanding that, for example, talent calibration means being made redundant or dismissed. It could equally suggest training aimed to develop the employee's skills or talents.

Some companies are so concerned with creating a positive image of their organisation and associations in their employees and customers that they draw up lists of words or phrases that cannot be used by staff. Such lists (or in some cases even manuals) include precise instructions specifying how they should be replaced. In his article on the BBC website, Johanson (2017) gives examples of such euphemistic newspeak. So in the Davio's restaurant chain the word employee has been replaced by inner guest and a restaurant visitor/guest is called an outer guest. Montreal-based company IT GSOFT changed the name of the HR department to Department of Culture and Organisation which is in charge of harmonising collective action. People who are not familiar with this specific lexis might have problems with understanding what an inner guest is or what the Department of Culture and Organisation deals with and whom to contact about personnel matters. Kane and Sherr (2011), two journalists from the Wall Street Journal, provide some even more interesting examples. They managed to get hold of the secret Apple inner manual for sales staff and they described in detail how staff was trained, in particular to communicate with clients and to prevent them from having any negative associations with equipment they were planning to buy or had already bought. The manual provides detailed information on what language should be avoided in which situations and recommends more politically correct and 'polished' equivalents. For instance, it recommends that items such as unfortunately, bug, crash, hot, problem be replaced by as it turns out, it's not responding, warm, issue/situation. The main aim of this is to avoid negativity related to company image. More facts about Apple can be found in Biddle's on-line article (2012). The new terms do not seem to be of much help to a client trying to understand a problem with faulty equipment. General Motors made another list of forbidden words consisting of 69 words which include, for example, defect, death trap or flawed. 
Polished messages and euphemistic camouflage diminish the scale of the real problem because a message deprived of its content becomes worthless. Biddle (ibid 2012) calls this language sterilisation, which results from improving reality excessively, and removing or replacing uncomfortable content. Positively-oriented language becomes "empty". In this way, instead of improving reality, company policies put constraints on employees and their interactions with clients since they need to follow rules on accepted linguistic behaviour. Consequently, clients are disorientated and employees are subjected to a kind of censorship.

According to the Sapir-Whorf theory, people's actions and ways of thinking are determined by the language they speak so one might wonder what the use is of implementing such communication "improvements".

\section{2 Creative function of euphemisms job titling and job duties}

The appearance of the Millennial generation on the labour market also led to changes in the language. Members of the Y-generation, surrounded by the latest technology, focus on good relationships at work, want to be creative and work with passion in companies based on human capital and that enable them to pursue their professional interests. For them language reduces stress, motivates and creates a positive attitude and relationships.

These priorities are reflected in work-related terminology and new, more positive and creative vocabulary is used to name new jobs and positions. The examples presented below come from the websites mentioned before and from The Definitive Dictionary of Deliberately Deceptive Language (2015), which contains numerous entries-quotations including samples of new creative lexis in various social contexts.

An interesting example is the word secretary, now seen as a blast from the past, which has been replaced with one of the following equivalents: area associate, administrative professional, executive assistant, office manager or personal assistant. Megan Carpentier in her article (2012) explains the reason for the change: "The word "secretary" conjures up images of a bygone era, of pearls and sweater sets, sensible heels and knee-length skirts, and the right mixture of efficiency and self-effacement to fade into the background while acting as a powerful man's right hand." As for the new position names, they denote career upgrade and professionalism, and acknowledge "the importance of administrative work and support to the success of many projects and even many people." (Carpentier ibid).

Here are some examples of terms for job positions used by recruiters, employers and/or employees: a receptionist is a telephone intermediary; marketing 
staff are marketing fellows; happiness heroes deal with customer care; a bouncer is called an eviction technician. Here are other examples from well-known companies: sandwich artist (Subway), genius (Apple), innovation sherpas (Microsoft), digital prophets (AOL), fashion evangelists (Tumblr), imageers (Walt Disney). There are also numerous ninjas (accounting ninja, office ninja, new product ninja) and an abundance of other terms related to IT jobs such as programming wizard, wizards, warriors, genies, vixens, web overlord to mention but a few. The Plain English website provides a list of creative job names coined by employers who want to better motivate their prospective and current employees. Some examples are presented in the table below:

Table 2. List of unusual job names coined by employers

\begin{tabular}{|l|l|}
\hline NEW TERM & OLD, TRADITIONAL TERM \\
\hline ambient replenishment controllers & shelf stacker \\
\hline foot health gain facilitator & Chiropodist \\
\hline head of verbal communication & Secretary \\
\hline knowledge navigator & Teacher \\
\hline $\begin{array}{l}\text { regional head of services, infrastructure } \\
\text { and procurement }\end{array}$ & Caretaker \\
\hline regulatory affairs associate & clerk sorting out documents \\
\hline revenue protection officer & ticket inspector \\
\hline space consultant & estate agent \\
\hline technical horticultural maintenance officer & Gardener \\
\hline
\end{tabular}

Professor Cable in his article (2017) on job titling discusses positive aspects of new job titles created by employees. "Your title can also have a big impact on your day-to-day happiness and engagement. Personally, I also see a job title as a form of self-expression in the workplace. It is a symbolic representation of what you do and the value that you bring." Grant, Berg and Cable (2014) claim that unusual, non-standard names of their (employees') job positions are important in both work and private life as they give them a sense of psychic safety by reducing stress and emotional exhaustion and making employees feel exceptional and appreciated. In their research they interviewed and observed employees from Make-A-Wish Foundation ${ }^{2}$ in order to analyse the impact that self-reflective job titles have on staff. When employees found titles helpful they described them positively: "having titles allows people to be themselves' or they 'make everybody more real." In general, their work shows job titles in a positive light. Now let us have a look at examples of these creative, self-reflective job names/titles.

2 A non-profit human service organisation in the US arranging special events called wishes for children with life-threatening conditions. It also operates in 45 other countries. 
Some companies allow their workers to create names for their job positions. Thus a Yahoo spokesperson is a Yahoo! Evangelist; sales staff at Quicken Loans are called Energy Focusers and Energy Raisers. Other self-reflective job titles listed by Grant, Berg and Cable (ibid) include: People and Culture Poet, Director of Chaos. In his blog, Kjerulf Matt Cadwell (2008) mentions that a Web Marketing Director at Quicken Loans became an Idea Salesman, Energy Focuser and People Unleasher. In his company he decided to 'kill' traditional job titles so he emailed employees and encouraged them to adopt new names for their job positions: "Here's your chance to create a title for yourself that will convey exactly how important you are. And because you are creating it, it will be all yours. No one else will have that title. [...]. Think of the opportunities it can create for you in terms of expressing who you are, not what someone CALLS you." Here are some examples of names coined by the staff who decided to express themselves in a more light-hearted way compared to traditional terminology: Royal Storyteller \& Propaganda Minister; Supreme Challenger of the Status Quo \& Wicked Web Site Innovator; Mastermind of Possibilities; Visual Linguist, and Czar of the High Fiber Revolution; Conceptologist; Head Brother In Charge of Chat; Sentence-smoother-outer with an Ad Girl twist; Pixelardo da Vinci. Many more examples can be found on the internet blogs.

Kimberly, Bouchikhi, \& Craig, (2001) claim that this can be seen as a tendency towards the customisation of individual experiences in organisations.

On the other hand, these names do not clearly define the employee's scope of duties and cause problems to other employees and work organisation. For example, whom should they contact if they have a problem with their computer: a wizard or a ninja? These terms reflect views and values but do not provide information about employee's skills or qualifications. Also, some of these names have childish connotations (e.g. reception rockstar). In his article (2014), Henry Goldbeck, Sales and Marketing Recruiter, Industrial Headhunter says "weird and wonderful" job titles in resumes can work for and against people during recruitment. "If it [the title] gets you attention, and makes a positive impression, great. If it tells your story, even better." But ninjas might not be found by recruiters. He goes on "In our data base, for example, we have seven ninjas. Here's how many we have interviewed: 0 . Here's how many we've hired or placed: 0 . LinkedIn recruiters do not read resumes, they use keywords to search data base to find candidates with specific skills and abilities, not unusual job titles. He advises candidates to use more standard terms and relevant keywords which "recruiters and employers are searching for." 
Every year Pearl and Meyer, an American consulting company publishes reports on job titling practices. For 2014 and 2018 the company presents the results of the survey conducted in the US in 248 (2014) and 219 companies (2018). There seems to be less linguistic creativity at managerial level. As for titling practices, the survey showed a preference for traditional titles such as Manager (82\%), Director (55\%) and Vice President (43\%).

Another area in which creative lexis is also found is job descriptions. This can be illustrated by an interesting example of business camouflanguage found in job descriptions from the Plain English website.

\section{Technical Enablement Leader}

"...has specific responsibility for ensuring that all aspects of New Business Technical Requirements are fully scoped both in gathering current infrastructural parameters of the sending organisation framework and in determining comparative requirements through exercise of due diligence on current and anticipated infrastructures to support ongoing business continuity in the Location. Specific responsibilities covered in due diligence exercise to incorporate the following task performance." (Plain English website)

\section{Administrative Assistant in the NHS Trust}

An exciting opportunity to join a newly formed Service Modernisation Team which will lead the drive for even better practice and will play a significant role in creating a self-generating culture of improvement.' (Plain English website)

Though the text itself is grammatically correct, due to its excessive sentence length and vague language it is impossible to identify the job that is described or what sort of job duties it involves.

Other problems might stem from the fact that companies use double terminology: internal (using creative language to attract potential employees) and external (standard) for foreign business partners and clients who might have problems with appropriate understanding or translating such doublespeak into their mother tongue due to the lack of appropriate equivalents. This might pose problems in the international business context of establishing the status of employees in the company hierarchy, the responsibilities of particular job positions and, generally, how the company works. 


\section{Bizspeak‡ office jargon, managerial speak vs, plain English}

Another category prone to creativity in a business context is the lexis related to work activities, consisting mostly of verbs and verb phrases which are used in a new metaphorical meaning and replace 'traditional' terminology. Table 3 below shows some examples of common office jargon.

Table 3. Examples of common office jargon related to office $\&$ business activity

\begin{tabular}{|c|c|}
\hline $\begin{array}{l}\text { CREATIVE, METAPHORICAL NAMES } \\
\text { OF ACTIVITIES }\end{array}$ & $\begin{array}{l}\text { TERM EXPLANATION/ } \\
\text { TRANSLATION IN PLAIN ENGLISH }\end{array}$ \\
\hline to have a helicopter view & to have a broad overview of the business \\
\hline to have an idea shower & to brainstorm \\
\hline to touch base offline & meet and talk face to face \\
\hline to punch a puppy & to do something horrible for the greater good \\
\hline to look under the bonnet & to analyse a situation \\
\hline to get all your ducks in a row & to be organised \\
\hline don't let the grass grow too long on this one & to work fast \\
\hline to cascade relevant information & to speak to your colleagues \\
\hline to run it up the flagpole & to try it out \\
\hline to (not) have enough bandwidth & be too busy \\
\hline to prepone & to bring forward, opposite of 'postpone' \\
\hline to square the circle & $\begin{array}{l}\text { to try to do something that is very difficult or } \\
\text { impossible }\end{array}$ \\
\hline to open the kimono & to share data \\
\hline to moof & to be mobile and out of office \\
\hline to outsource & to rightshore \\
\hline to have a biobreak & go to the toilet \\
\hline to boil the ocean & waste time \\
\hline
\end{tabular}

In the UK the Plain English Campaign was launched in 1979 and focused on fighting for clear communication in the public domain (e+g. government, banks, health care) without unnecessary gobbledygook, jargon and misleading information. The campaigners identify common verbiage in documents and help organisations eliminate it and improve the quality of information. On their website (2017) the campaigners try to account for the popularity of office jargon (e.g. the items in the above table). The first reason they give is that many jobs in the office are rather simple so jargon makes the tasks seem more exotic and employees feel "a little more important, some use jargon to make their role sound more complex. (...) If they spoke honestly, concisely and clearly about what they did, everyone would quickly realise that what they do is not only quite dull, but also quite easy." The second reason lies in the fact that this mode of communication makes staff feel like an exclusive group and emphasises their role 
in the organisation. Hence, it gives a sense of importance to one group while others are excluded by a jargon barrier. Some employees use office speak rather unwillingly and only to adapt to the terminology used in their workplace.

In some cases the rationale for new equivalents can be surprising. For example, to some people brainstorm is an offensive term since it might offend people with epilepsy so it was replaced with idea shower. Interestingly, in 2005 the National Society for Epilepsy in the UK conducted a survey which showed that the majority of its members found the term inoffensive. Another example is saying that something is actionable instead of something will work. The examples in the table and the two mentioned above have no information value to somebody who is not familiar with the jargon since they contain no key words which might evoke correct associations and ensure precise interpretation. Consequently, they obscure meaning, impede efficient communication and become a source of exclusion to people who are not members of the specific group using the jargon. This can pose problems for other company employees, business partners or translators. Using two systems of terms (i.e. the traditional ones and the new ones) can be misleading, particularly to foreigners who do not know the company jargon or do not have a sufficient command of the language to identify connotations and metaphorical meanings. In many cases, long phrases replace what could be expressed in one unambiguous word (for example, why should we look under the bonnet or drill sth down if we can simply analyse it?). Additionally, in international business, the associations evoked by euphemisms may differ and if they are translated word for word to another language, they become meaningless. Any attempt to convey a metaphorical meaning may prove to be unsuccessful because of differences between languages not only in terms of grammar or lexis, but because the meaning is also socially and culturally determined and to some extent untranslatable.

Office jargon has been doing well for years and many newspapers (e.g. The Guardian, The Daily Telegraph) regularly publish lists with samples and hold a vote for the most hated items.

\section{Conclusions and... exclusions}

\section{Correctness and politeness}

The idea of political correctness seems to have evolved in an unpredictable direction. It aimed to improve reality by not discriminating against minority groups who are oppressed to some extent or another. It assumed that changes and/or modifications could be made to do away with undesirable linguistic and 
non-linguistic behaviours that might lead to offence or exclusion. In the area of language a number of modifications have been suggested with regard to:

1. naming/titling potential minorities or groups of people who might be subjected to discrimination (ethnic or racial minorities, women, ill or old people, people with different sexual orientations, religious groups, people with lower job positions etc.); things or activities they do in their private lives (e.g. observing public and religious holidays);

2. work-related terminology (job names/titling, names of actions and activities, jargon related to specific jobs and duties used in communication with co-workers or clients, recruitment process and participants [e.g. ways of addressing people]);

3. politics - political correctness in this area as in some cases it may be difficult to make a clear distinction between being PC and censorship and limiting freedom of speech;

4. health problems and disabilities - terminology emphasising people not their illnesses;

5. other areas.

Implementing the recommended modifications and improvements requires some notions and terms to be eliminated, and replaced with "correct" ones. This is why lists of forbidden words are created. One might wonder to what extent banned vocabulary is "bad" and if it is not an attempt to censor people through their language and behaviour. However, there are no clear-cut rules or criteria to establish what is correct. Correctness is relative, particularly in the case of English, the lingua franca used all over the world because there are different standards of political or linguistic correctness and politeness. In the international context (e+g, in multi-national organisations), language-specific properties and cross-cultural differences should be taken into account when establishing what is or is not politically correct. For example, the way to address people differs: you in English may be impolite in other languages, which would use $M s$ and $\mathrm{Mr}$ to avoid offence. In English, using job names with gender implications is not recommended (e.g. stewardess, businesswoman, chairman should be replaced, respectively, with flight attendant, business executive and chairperson). In contrast, Polish women's movements and the Council of the Polish Language recommend using feminine forms, though it is not obligatory. 


\subsection{Interpretation problems - translatability, language proficiency}

New improved language can be convenient for quick effective communication in the workplace. On the other hand, these modifications and improvements can lead to asymmetrical relations because a group of people creates a code that is known only to them and excludes outsiders who do not belong to the group and are not "in the know". Even native speakers admit that they have problems understanding it. Watson (2017) reports that constantly developing corpspeak may be difficult for foreigners to follow because of their fluency in English (or lack of it) and their limited ability to recognize and interpret word connotations and linguistic nuances. Some concepts in one language are absent or untranslatable in another. The language of a particular culture imposes the way of conceptualising and structuring its reality (Winkler 2008). The structure of the mother tongue creates in native speakers certain ways of thinking and perceptions of the world. Szymczyk-Rozlach (2014) points out that the correct interpretation of euphemistic notions can pose a serious problem to both researchers and native speakers since understanding the right meaning of vocabulary items "requires extraordinary intuition and high level of language proficiency, particularly the skill of finding hidden meanings of words that are frequently camouflaged."

Technically speaking, this means that only native speakers or English speakers with the C2 level of the Common European Framework of Reference for Languages (CEFR) will be able to understand these terms. ${ }^{3}$ These skills are described in the CEFR scale in the can-do description of Proficient Users (C2): "Can express him/herself spontaneously, very fluently and precisely, differentiating finer shades of meaning even in more complex situations." Not many people in business can boast of language competence at this level despite their ability to communicate fluently and effectively. As for the translation of bizspeak there might be a need for intratranslation or intertranslation. The former refers to translation within a specific language (e.g* explaining meanings and concepts, also for adults) whereas the latter "transfers' the message from one language to another.

3 <https://www.coe.int/en/web/common-european-framework-reference-languages/table-1-cefr-3.3common-reference-levels-global-scale $>$ 


\subsection{Family of Englishes}

Another issue that needs to be tackled is that there is no one model of an English native speaker since the English language has expanded to all continents and its contact with local languages has led to the emergence of new varieties of English known as World Englishes. They have evolved, glocalised and been subject to various social contexts and standards of correctness worldwide, both linguistic and political. This defragmentation of English in combination with varied levels of English fluency affects the quality of communication between native speakers and non-native speakers. Winkler (2008) claims that in local and international contexts both parties participating in communications tend to create (encode) the meanings of the messages they send to others and interpret (decode) messages sent by others in accordance with their 'home' communication system. Thus, differences and discrepancies between rules of interpretation and interaction can disturb communication. At the language level this can be caused by language mistakes occurring in the production or interpretation phase. Winkler (ibid) states that effective communication occurs only when interpretation of a decoded message is in compliance with the sender's message. Ferraro (2002) also points out other key linguistic factors that limit effective communication. These include insufficient knowledge of proverbs and sayings, social stereotypes and categories of communication taboo; kinds of euphemism 'disguised' by the communication taboo; slang and jargon typical of a particular social or professional group; the specificity of the local sense of humour; types of verbal ritual typical of a particular community.

In international contacts there is a need for clear unambiguous communication that does not use figurative language full of impressive euphemisms and metaphors. So perhaps it will be easier and more practical "to call a spade a spade" instead. However, there is no one standard clear-cut definition of the taboo or what is politically correct in specific geographical, social or other contexts. Another interesting research question might be how the rapidly developing Englishes worldwide relate to the local languages. Local languages are confined to smaller communities and are used within well-defined territories, native speakers have a bigger influence on their language than English speakers do and the proportion of native speakers to non-native speakers is much higher than in the case of the UK or the USA. English no longer belongs to its native speakers. Millions of non-native speakers contribute to the development of English and Englishes, and undoubtedly English is present in local languages but the relationship between them is definitely assymetrical. It would be interesting if we could determine to what extent they permeate each other. Corpspeak quickly 
sneaks into local languages and English terms are often used in the original English or mixed with the mother tongue, which leads to varieties like Franglais, Denglish, Japlish, Ponglish and many others. This has a negative effect on their standards as the quality of both languages deteriorates, and they become incomprehensible to other employees and a tool of exclusion or discrimination. As for the ideas and postulates of political correctness at work, it seems that attempts to avoid negativity, unsuitable topics or some linguistic behaviours can be harmful. Paradoxically, eliminating and regulating certain language behaviours leads to other sorts of discrimination, and does not contribute to employee effectiveness or creativity. No matter where employees work, they will have to face problems from time to time and they need to discuss and solve them. In these situations, sterilised politically correct language will not be of much help. From the organisational perspective, the use of this sort of language is not altogether appropriate either because the terminology related to job titles/names, job duties, job descriptions, scenarios or manuals for communication with clients does not provide managers, employees and their co-workers or recruiters with appropriate information. Using double terminology (creative and traditional) can cause unnecessary confusion: some may not know what the official version is that needs to be stored in employee's record or used in contracts and other documents. This could also incur additional costs. Another issue worth considering is how helpful creative terminology is in a company's day-to-day operation. Traditional terminology gives information about an employee's place in the hierarchy, his/her qualifications and scope of duties. And that is what employees at all levels need to know to cooperate with others and work effectively.

At first the concept of political correctness seemed to be a good idea because it aimed to eliminate discrimination and offensive behaviour in the workplace and elsewhere. Now, however, it has come in for a lot of criticism since it imposed unrealistic regulations on people and led to a different sort of discrimination. Professional jargon is not a bad thing as it can make communication easier and faster, which leads to better and more effective communication and better workplace relationships. Other changes regulating linguistic behaviour should aim to improve working conditions and not introduce ideas that actually contradict the ideas of political correctness and turn against people.

Summing up, I would like to quote Quintillian, a Roman rhetorician: "One should aim not at being possible to understand, but at being impossible to misunderstand." Only this can ensure successful communication. 


\section{References}

Allan, K.1986. Linguistic Meaning (Vols 1 and 2). London: Routledge and Kegan, Paul. Beard, H. Cerf, C. 2015. The Definitive Dictionary of Deliberately Deceptive Language. Blue Rider Press.

Biddle, S. 2012. "How To Be a Genius: This Is Apple's Secret Employee Training Manual". <https://gizmodo.com/5938323/how-to-be-a-geniusthis-is-apples-secret-employee-training-manual> [accessed: 20 Oct. 2017]

Cable, D.M. 2017."How to Ask for the Job Title You Deserve". <https://www. linkedin.com/pulse/how-ask-job-title-you-deserve-dan-cable> [accessed: 10 Oct. 2018].

Carpentier, M. 2012. 'Secretary' title is a blast from the past <https://edition. cnn.com/2012/04/12/opinion/carpentier-secretaries-buffett/index. html $>$ [accessed: 5 Sept 2018]

Council of Europe. "Common European Framework of Reference for Languages. Global Scale - table 1(CEFR 3.3): Common Reference levels". $<$ https://www.coe.int/en/web/common-european-framework-referencelanguages/table-1-cefr-3.3-common-reference-levels-global-scale> [accessed: 10 Oct.2018].

Engelking, A. 1984. Istota I ewolucja eufemizmów(na przykładzie zastępczych określeń śmierci). In: Przegląd Humanistyczny no.4, 115-129

Ferraro, G.P. 2002. The Cultural Dimension of International Business, Prentice Hall, Upper Saddle River, New Jersey.

Grant, A.M. "The Wharton School, University of Pennsylvania”, Berg J. M. The Wharton School, University of Pennsylvania, D. M. CA B LE, London Business School "Job Titles as Identity Badges: How Self-Reflective Titles can Reduce Emotional Exhaustion" in: Academy of Management Journal 2014, Vol. 57, No. 4, 1201-1225. http://dx.doi.org/10.5465/amj.2012.033. [Accessed: 1 June 2018].

Kane, Y.I.; Sherr (2011) “Secrets From Apple’s Genius Bar: Full Loyalty, No Negativity". Wall Street Journal on-line, <https://www.wsj.com/articles/SB 10001424052702304563104576364071955678908>; [accessed: 20 Nov 2017.

Kimberly, J. R.; Bouchikhi, H., \& Craig, E. F. 2001. "The customised workplace: A Copernican revolution or a romantic fantasy?" European Business Forum, 6: 12-13.

Krawczuk-Tyrpa, A. 2001. Tabu w dialektach polskich. Akademia Bydgoska im. Kazimierza Wielkiego. 
Plain English Campaign <http://www.plainenglish.co.uk/campaigning/ examples/job-titles.html> [accessed: 15 Oct. 2018].

Goldbeck, H. 2014. Weird Job Titles Make Us Smile, But They're Not The Keywords Employers Search For. [accessed: 5 Oct. 2018]

Pearl and Meyer. Reports on job titling practices. Reports from 2014 and 2018: $<$ https://www.pearlmeyer.com/2018-job-titling-practices-survey-reportpreview.pdf $>$ [accessed: 10 Oct.2018].

Peters, M. 2017. "The hidden danger of euphemisms". <http://www.bbc.com/ capital/story/20170126-the-hidden-danger-of-euphemisms >; [accessed: 15 Oct.2018].

Pinker, S. 2002. The Blank Slate: The Modern Denial of Human Nature. Penguin Group.

Rozlach-Szymczyк, M. 2014. Eufemizmy we wspótczesnym języku stowackim. Wydawnictwo Uniwersytetu Śląskiego.

Ullmann, Stephan. 1962. Semantics. An Introduction to the Science of Meaning. Oxford 1962.

WaAtson, D. 2017. Are tech job titles elitist? New study reveals buge comprehension gap. $<$ https://www.google.com/search?q=are+tech +job+titles+elitist\&ie= utf- $-8 \&$ oe $=$ utf $-8 \&$ client $=$ firefox $-\mathrm{b}>$

WinkLer, R. 2008. Zarzadzanie komunikacja w organizacjach zróżnicowanych kulturowo. Oficyna Wolter Kluwer business. 